\title{
In memoriam Martin Warnke
}

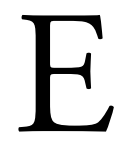

1 II de diciembre de 2019 murió Martin Warnke, uno de los más influyentes historiadores del arte en Alemania y de alcance internacional. Su trascendencia intelectual es plurifacética. Se manifiesta, en primer lugar, en la recuperación de la herencia conceptual de Aby Warburg en su lugar de origen, la ciudad de Hamburgo. Como profesor en la Universidad de Hamburgo (1978 a 2003), Warnke gestionó la reapertura de la Biblioteca de Ciencias Culturales, Kulturwissenschaftliche Bibliothek Warburg, como centro de investigación —el emblemático lugar que personajes como el propio Warburg, Erwin Panofsky y Ernst Cassirer, perfilaron como laboratorio de pensamiento innovador durante la década de los años veinte del siglo pasado. ${ }^{I}$ Warnke era el decano de la nueva escuela de Hamburgo, el verdadero sucesor de la cátedra de Historia del Arte que Panofsky detentó entre I92I y 1933. Esta nueva escuela consistió en un "triunvirato" con Horst Bredekamp y Klaus Herding, quienes establecieron y fortalecieron la historia social del arte en el esquema universitario, en una época en la que la disciplina era todavía muy conservadora. La biografía de Martin Warnke, quien luchó durante los últimos is años de su vida contra un cáncer, no fue lineal. Abordo aquí algunas facetas de esta trayectoria intelectual sobresaliente, los productos y los estimulantes efectos que éstos produjeron. Conviene ampliar este marco de comprensión biográfica

* Texto recibido el I9 de junio de 2020; devuelto para revisión el 9 de noviembre de 2020; aceptado el 29 de enero de 202I; https://doi.org/IO.2220I/iie.18703062e.202I.II9.2767

I. Erwin Panofsky, "A. Warburg (Nachruf)”, Repertorium für Kunstwissenschaft, núm. 5I (1930): I-4 (primera edición Hamburger Fremdenblatt, 28 de octubre de 1929; reeditado en Erwin Panofsky, Deutschsprachige Aufsätze, eds. Karen Michels y Martin Warnke, Studien aus dem Warburg-Haus, vol. I (Berlín: Akademie Verlag, I998), IIII-III4. 


\section{DOI: https://doi.org/10.22201/iie.18703062e.2021.119.2767}

430

PETER KRIEGER

porque, en innumerables casos, los obituarios se reducen a la renarración lineal de una carrera exitosa y no toman en cuenta que las complejidades y dificultades en la vida enriquecen la experiencia y nutren la creatividad del pensamiento.

En su discurso para el acto solemne de la Universidad de Dortmund, que en 20 io le otorgó el Doctorado Honoris Causa, Warnke reveló un detalle desconocido de su biografía que inició con su nacimiento en Ijuí, un lugar remoto en el sur de Brasil, en 1937. Su padre era pastor protestante luterano en una comunidad indígena. El público en Dortmund y después los lectores del discurso, cuando fue publicado, ${ }^{2}$ se sorprendieron al conocer el complejo contexto familiar del homenajeado: el abuelo de Martin Warnke era un sastre pobre en la ciudad de Jena, al este de Alemania. Por sus limitaciones económicas, envió a su hijo a trabajar como ayudante menor en una oficina de escribanos. Por fortuna, el pastor de la congregación luterana del lugar observó el talento del joven y financió sus estudios escolares superiores y luego universitarios de teología protestante. Ese pastor, August César, se inclinó por una teología liberal con compromiso social, lo que incluyó el fomento a la educación juvenil de las clases bajas.

Para la mejor comprensión de la ética académica de Martin Warnke, es importante perfilar al mecenas de su padre. Resumo su discurso de 20IO: en I906, el nombramiento de César como pastor de la congregación luterana en la iglesia Reinoldi Dortmund —el mismo lugar de la celebración de su Doctorado Honoris Causa - fue rechazado por la autoridad eclesiástica, porque el candidato enfocó su concepto pastoral en el trabajo social y cuestionó las bases dogmáticas de las religiones cristianas. César negó la virginidad de María, al afirmar que Jesús había nacido como cualquier otro ser humano. También rechazó los "milagros", como la resurrección de Lázaro, lo que entendió como una desviación inoperante para la práctica de la fe. Defendió su postura racionalista en cuanto a que la reanimación de un cadáver en proceso de descomposición es físicamente imposible. Y, por lo mismo, cuestionó la resurrección física de Jesús de la tumba, al indicar que este presunto milagro no tiene valor didáctico para el mensaje de paz en la esencial fiesta cristiana de Pascua.

Tal postura liberal se enfrentó con la autoridad conservadora del entonces imperio alemán, donde el Kaiser fungía también como máximo representante,

2. Martin Warnke, “Der 'Fall César' in der Reinoldigemeinde zu Dortmund I906”, en ed. Barbara Welzel, Beunruhigung durch Kunst und Wissenschaft, Dortmunder Schriften zur Kunst, Studien zur Kunstgeschichte, Band 4 (Norderstedt: Books on Demand GmbH, 20II), I3-2I. 
I. Martin Warnke a la entrada de

la Warburg Haus, Hamburgo, Alemania, 2016. Foto: Peter Krieger.

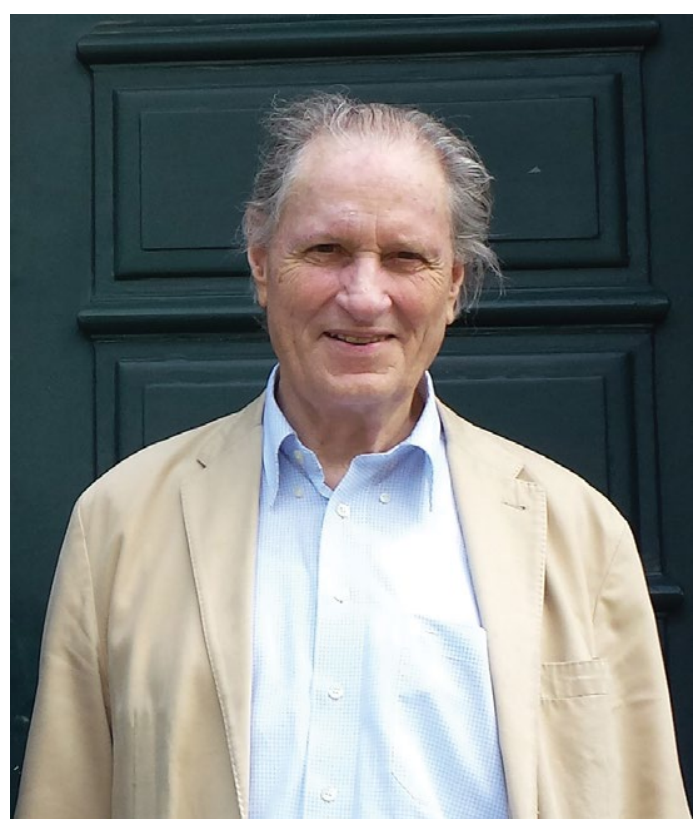

Summus Episcopus, de la Iglesia protestante. Se discutieron las posturas de César en la prensa nacional e incluso en el parlamento prusiano. Era un caso paradigmático de la época, un politicum. Como resultado, el puesto en Dortmund se le negó a César, y por ello se quedó en la zona rural y empobrecida cercana a Jena, en su propia comunidad, con su trabajo pastoral, sociopolítico.

Para Martin Warnke, este background familiar definió los parámetros éticos de toda su vida, en concreto: insistir en la libertad de la conciencia frente a cualquier represión política o eclesiástica; desenmascarar el abuso de un credo como instrumento de poder político, además de luchar contra las injusticias clasistas y represoras; fomentar la educación sin restricciones para todas las clases sociales, siguiendo el concepto del Bildungsprotestantismus, del protestantismo liberal-educativo - todos ellos valores de la Ilustración del siglo XviII, determinantes para la vida académica de Warnke. Por supuesto, dentro de este marco ético-religioso hoy es cuestionable establecer una misión cristiana en una comunidad indígena, ya que es un acto colonial, aunque cabe aclarar que, en este caso, el protestantismo luterano no operó con las herramientas de control psíquico-colectivo como es usual en las actuales sectas evangelistas en 


\section{DOI: https://doi.org/10.22201/iie.18703062e.2021.119.2767}

432

PETER KRIEGER

América Latina, financiadas por megaempresas estadounidenses para controlar los territorios políticos del subcontinente. El joven Martin Warnke aprendió la lección de vivir como miembro de una minoría, practicando y exigiendo tolerancia. Su padre huyó de la dictadura nazi en Alemania y educó a sus hijos con un espíritu crítico e ilustrado.

Horst Bredekamp, alumno, colega y amigo cercano de Warnke, resumió esta conducta ética en una frase breve y reveladora: "El hijo de un predicador, por toda su vida, tuvo una postura escéptica frente a las grandes palabras." ${ }^{3} \mathrm{Y}$ la herencia productiva del protestantismo que proporcionó las bases conceptuales de la filología crítica (Schleiermacher et al.), vigente en el pensamiento de Warnke, se resume en la capacidad de cuestionar e incluso relativizar su propio pensamiento.

El producto más obvio de esta determinación familiar fue la asesoría de Warnke en el proyecto curatorial del museo de Hamburgo, Kunsthalle, sobre Lutero y las consecuencias para el arte, Luther und die Folgen für die Kunst, ${ }^{4}$ en 1983, y su libro sobre los retratos de Lutero que hizo Cranach, Cranachs Luther, un análisis puntual de las estrategias mediáticas de la Reforma protestante y su máximo artista Cranach —una investigación inspirada por la publicación inicial de la iconografía política de Aby Warburg. ${ }^{6}$

Por la ética pacifista de la familia Warnke, enviaron al adolescente Martin en 1953 a Alemania, porque el padre no quería que su hijo se incorporara al obligatorio servicio militar brasileño. La terrible experiencia con la dictadura nazi y su aparato militar, pero también los frecuentes excesos violentos, los golpes de Estado perpetrados por militares en casi toda América Latina — realidad brutal en Brasil con la dictadura militar de 1964 a 1985, recién reanimada por el actual presidente fascista de este país, Jair Bolsonaro- eran una advertencia. También el tema de las dictaduras, su promoción por medio de

3. Horst Bredekamp, "Rubens, Warburg und die Couchecke. Der Kunsthistoriker Martin Warnke revolutionierte sein Fach. Jetzt ist er gestorben”, Süddeutsche Zeitung, I2 de diciembre de 2019.

4. Werner Hofmann, ed., Luther und die Folgen für die Kunst, catálogo del Kunsthalle Hamburg (Múnich: Prestel, 1983).

5. Martin Warnke, Cranachs Luther. Entwürfe für ein Image (Fráncfort del Meno: Fischer, 1984).

6. Aby Warburg, "Heidnische Weissagung in Wort und Bild zu Luthers Zeiten", en ed. Bibliothek Warburg, Band II, en colaboración con Fritz Rougemont, ed. Gertrud Bing, $A$. Warburg / Gesammelte Schriften (Berlín: B.G. Teubner, 1932), 487-565. 
esquemas iconográficos, que Warnke investigó en su vida académica, tienen raíces biográfico-familiares.

Como joven inmigrante en la parte occidental de Alemania, Warnke acudió a escuelas en Gütersloh y Dortmund, y terminó el bachillerato en Darmstadt. Fue en esta fase de maduración, cuando hizo largas excursiones en bicicleta para visitar los museos de la cercana ciudad de Fráncfort, pero también a las amplias colecciones de arte en Múnich y otras ciudades. Estudió Historia del Arte, Letras Alemanas e Historia en las universidades de Múnich y Berlín, donde se doctoró (a los 27 años) en I963; su tesis versó sobre el principio de la dissimulatio en la obra de Peter Paul Rubens. ${ }^{7}$ Cabe mencionar que dicho trabajo se basó en una estancia de estudios en Madrid. Warnke era un pionero de la hispanística en la historia del arte en Alemania, que continuaba el legado de Carl Justi, en tiempos en los que la mayor atención académica en su disciplina se orientaba hacia el arte italiano y francés.

Su tesis tuvo ya el germen de una pasión intelectual que Warnke siguió por toda su vida: la iconografía política. El término de la dissimulatio apareció en una carta de Rubens al rey Luis XIII en cuanto al ciclo Medici y parafraseó un principio de Cicerón, descrito como instrumento político por Maquiavelo: una verdad encubierta, disimulada por una construcción iconográfica afirmativa en una pintura, puede fungir como crítica al soberano; entonces surge la paradoja de que el acto de encubrir también es un acto, irónico, subversivo, a la vez, de revelar. Para descifrar estos mensajes en la obra del pintor y diplomático Rubens, Warnke estudió las cartas en los archivos (de la corte en Madrid), y utilizó una sólida base historiográfica y filológica para su investigación doctoral, que le permitió iniciar reflexiones sobre la iconografía política, en ese caso, sobre las misiones diplomáticas de Rubens por medio de la pintura.

Warnke relacionó la producción artística en sus múltiples contextos políticos, filosóficos, literarios y sociales —durante los años sesenta, en una fase todavía muy conservadora de la historiografía del arte en Alemania, que había ignorado el trabajo pionero de Erwin Panofsky—, pero al mismo tiempo siempre insistió en la autonomía de la forma, que genera sus propios impulsos más allá de la palabra. He ahí un punto neurálgico de nuestra disciplina que todavía, en muchos casos, determina el sentido de una obra artística con base en

7. Una revisión posterior de este concepto contiene Dissimulazione onesta oder die ehrliche Verstellung. Von der Weisheit der versteckten Beunruhigung in Wort, Bild und Tat. Martin Warnke zu Ehren, ed. Horst Bredekamp (Hamburgo: Philo, 2007). 


\section{DOI: https://doi.org/10.22201/iie.18703062e.2021.119.2767}

nociones filosófico-literarias, sin tomar en cuenta el propio lenguaje visual del arte - un problema presente incluso en la crítica del arte contemporáneo, que reduce una propuesta plástica a su posible sentido filosófico. ${ }^{8}$

Aun como iconógrafo convencido, Warnke nunca optó por el camino fácil, el mainstream, sino siempre mantuvo su distancia escéptica y crítica frente a cualquier rutina de interpretación. Eso caracterizó también su postura y actuación en el contexto del año clave 1968. Nunca fue un "altavoz" de esta generación hondamente politizada y rebelde, sino una voz sutil, pero firme, con base en su inteligencia, no en ideología panfletaria. Su capacitación política la recibió definitivamente entre los años 1963 y 1965, cuando trabajó como observador y reportero de los juicios de Auschwitz, donde se reveló con todo detalle la barbaridad de la dictadura nazi en Alemania. En una serie de artículos - de nuevo publicados como libro hace algunos años— ${ }^{9}$ Warnke analizó la estructura de la violencia fascista, y a partir de ello, empezó a formular preguntas a la generación de sus profesores de historia del arte en Alemania, con trayectorias oportunistas en el sistema nazi.

El trabajo como periodista también le sirvió como un entrenamiento para explicar los más complejos asuntos en un lenguaje sencillo, pero muy preciso. Su gusto por la formulación aguda, incluido su manejo experimental por medio de metáforas, todo presentado en esquemas sintácticos claros, desembocó en un estilo personal, que muchos intentaron copiar sin éxito. En una disciplina que sufre por cantidades exponenciales de fraseología $u$ otras incapacidades de escritura, sus textos despertaron un amplio interés, no sólo por los contenidos, sino por su capacidad de concreción y precisión, de dar "en el clavo".

Hago un paréntesis para comentar que resulta muy difícil traducir su estilo al español, experiencia que me quedó grabada por mi trabajo como coeditor de un volumen sobre terminologías de la Historia del Arte, en el que incluimos un texto de Warnke, "Sobre la evolución de la técnica de periodización en la historia del arte del siglo XIX" ${ }^{\text {10 }}$ La revisión y corrección de esta traducción ha sido uno de mis trabajos editoriales más difíciles.

8. Expliqué este mecanismo de reducción interpretativa en mi artículo "Words don't come easy - comentarios a la crítica y exposición de las artes plásticas actuales", Revista Universidad de México, núm. 597-598 (octubre/noviembre de 2000): 25-29.

9. Martin Warnke, Zeitgenossenschaft. Zum Auschwitz-Prozess 1964, introd. Pablo Schneider y Barbara Welzel (Zúrich: Diaphanes, 20I4).

ı. Martin Warnke, "Sobre la evolución de la técnica de periodización en la historia del arte del siglo XIx”, en Patricia Díaz, Montserrat Galí y Peter Krieger, eds., Nombrar y explicar (Méxi- 
Su sensibilidad por las estructuras retóricas — reconocida por la Nueva Academia de la Lengua (Neue Fruchtbringende Gesellschaft, NFG, refundación de la Academia de I6I7) en Köthen, Alemania, donde lo nombraron miembro fundador en 2007- fue una importante capacitación académica para la mordaz crítica política de la historiografía del arte alemana durante las primeras dos décadas después del fin del nazismo. Sin balconear nombres, pero con precisión filológica, analizó las inherentes posturas ideológicas nacionalistas, de un peligroso populismo de derecha, con tintes nazis, en las publicaciones de innumerables historiadores del arte. Con apenas 32 años de edad, Warnke se lanzó contra la generación de sus maestros, quienes revelaron, en sus textos, ciertas continuidades del pensamiento autoritario de un sistema dictatorial. Warnke atacó un establishment académico, cuyas categorías de análisis promovieron valores cuestionables como "subordinación”, "abnegación” y "sumisión" — todo ello virtudes de un sistema totalitario marcial. Con elegancia filológica, pero también con firmeza intelectual, el joven investigador clasificó la producción académica de esta generación posnazi como acto de subyugación —en términos freudianos: mató a sus padres. La publicación de este análisis y de textos de otros colegas de la generación del 68 comprobó toda esa crítica en detalle, con un amplio aparato crítico. ${ }^{12}$

Otro paréntesis: en el caso alemán ésta fue una importante contribución al proceso de desnazificación, sustentado por la Escuela de Fráncfort, en el campo de la filosofía social. Pero también en México y en muchos países latinoamericanos cuyas historiografías de arte durante varias décadas del siglo pasado se concentraron en un nacionalismo retrógrado, tal crítica depuradora fue necesaria, tarea que acometieron varias generaciones de historiadores del arte, aún activas.

Para Warnke, esta publicación marcó un punto crítico en su carrera, porque los colegas que se sintieron atacados orquestaron una campaña en contra de él y su rebelde generación. Por un tiempo, pareció que no lograría continuar con su carrera universitaria; era persona non grata en la mayoría de las cátedras

co: Universidad Nacional Autónoma de México-Instituto de Investigaciones Estéticas, 20I2), 29-5I.

II. En alemán: Unterordnung, Selbstaufgabe, Unterwerfung.

I2. Martin Warnke, "Weltanschauliche Motive in der kunsthistorischen Populärliteratur", en Martin Warnke, ed., Das Kunstwerk zwischen Wissenschaft und Weltanschauung (Gütersloh: Bertelsmann-Kunstverlag, 1970), 88-I08. Véase también Otto K. Werckmeister, "Radical Art History", Art Journal 42, núm. 4 (1982): 284-29I. 


\section{DOI: https://doi.org/10.22201/iie.18703062e.2021.119.2767}

436

PETER KRIEGER

de historia del arte en Alemania. Ya buscaba otras alternativas para el ejercicio de su profesión, cuando las dos sedes más progresistas de la disciplina, en su momento, la Universidad de Marburgo y luego la Universidad de Hamburgo, lo contrataron como profesor de tiempo completo —en Marburgo de 197I a 1978, donde educó a toda una generación de estudiantes, entre los cuales destaca Horst Bredekamp, y en Hamburgo, de 1978 hasta su jubilación en $2003 .{ }^{13} \mathrm{Su}$ contratación en Hamburgo fue un reconocimiento explícito a la historia social del arte que Warnke promovió y, aún más importante, un llamado a continuar la tradición iconográfica que Panofsky fundó en esta Universidad en los ańos veinte, hasta su emigración a los Estados Unidos con el auge de la dictadura nazi. Siguiendo esta línea con persistencia profesional, Warnke se dedicó al rescate y reanimación de la olvidada tradición de Aby Warburg, académico independiente, contemporáneo de Panofsky, inspirador de un nuevo concepto de la historia del arte como "ciencia cultural" (Kulturwissenschaft).

Surgió la segunda escuela de Hamburgo, dedicada a una refrescante reconceptualización de la disciplina, fundada en Panofsky y Warburg. Después de un largo intermedio entre 1933 y 1978 con catedráticos de alguna manera relacionados con el sistema nazi, Warnke fue el verdadero sucesor de Panofsky. Y gracias a su iniciativa reabrieron la Warburg Haus en I99I como centro de investigación en ciencias culturales, ${ }^{14}$ en cercana colaboración con el Warburg Institute de la Universidad de Londres.

Mientras tanto, la difusión de la obra académica de Panofksy y de las inspiraciones intelectuales de Aby Warburg generó un boom que continúa hasta la fecha. Destacan académicos inteligentes, con talento para la autopromoción, como Kurt Forster — con quien Warnke estudió en Múnich-, David Freedberg y Georges Didi-Huberman, ${ }^{\mathrm{IS}}$ promotores de la llamada "industria War-

13. Martin Warnke, Bau und Überbau. Soziologie der mittelalterlichen Architektur nach den Schriftquellen (Fráncfort del Meno: Suhrkamp, 1984 [primera ed. Fráncfort del Meno: Syndikat, 1976]); Martin Warnke, Hofkünstler. Zur Vorgeschichte des modernen Künstlers (Colonia: DuMont, 1996 [segunda edición; traducción al italiano: Artisti di corte. Preistoria dell'artista moderno. Roma: Istituto della Enciclopedia Italiana, 199I]).

I4. www.warburg-haus.de (consultado el I3 de junio de 2020).

15. Véase Georges Didi-Huberman, Das Nachleben der Bilder. Kunstgeschichte und Phantomzeit nach Aby Warburg (Berlín: Suhrkamp, 20Io) por, David Freeberg, "Pathos a Oraibi: Ciò che Warburg non vide", en Claudia Cieri Via y Pietro Montani, eds., Lo Sguardo di Giano, Aby Warburg fra tempo e memoria (Turín: Nino Aragno, 2004), 569-6II; y David Freeberg, "Warburg's Mask: A Study in Idolatry", en Mariet Westerman, ed. Anthropologies of Art (Williamstown: Clark Institute, 2005), 3-25. 
burg" lo que, de alguna manera, ha opacado la labor fundacional de Warnke en Hamburgo. Incluso con estos contextos discursivos Warnke mantuvo una distancia crítica.

Por ejemplo, cuestionó ciertas formulaciones de Warburg, algunas que radican en la psicología y etnología colonial de alrededor de 1900; también contó que Warburg manejó las consultas públicas de su biblioteca de ciencias culturales como un tirano, puesto que interrogaba a cada solicitante y los obligaba a leer ciertos títulos que él mismo seleccionaba; o, reveló que el colega contemporáneo Heinrich Wölfflin, aparentemente más conservador, se opuso con mayor claridad y firmeza a la primera guerra mundial, que Warburg. En una palabra, Warnke evitó el elogio vacío y con ello apreció más la postura distante a Warburg que caracteriza a la biografía intelectual de Ernst H. Gombrich. ${ }^{16}$

Desde una sólida base del conocimiento de las diferentes posiciones y metodologías, Warnke ejerció un principio de tolerancia. Pero intervino tajantemente cuando un conocimiento, un concepto, se estandarizó, como es el caso del muy conocido esquema tripartita de la iconografía ${ }^{17}$ —un patrón fijado como camisa de fuerza para diversas generaciones de historiadores del arte en el mundo. Dixit Warnke: "No considero fructífero utilizar los famosos esquemas de interpretación que nadie, menos el propio Panofsky, verdaderamente aplicó." ${ }^{18}$

Warnke mantuvo cierta desconfianza frente a las "metodologías" que tienden a reducir la complejidad del pensamiento y de su producto, la interpretación. Optó por una pluralidad de métodos, además por una libertad de reflexión, sin tabúes, sin restricciones ideológicas. Su simpatía por los sistemas abiertos del pensamiento encontró un equivalente en la obra de Warburg, en especial en su Atlas Mnemosyne con sus combinaciones temáticas de imágenes procedentes de diferentes épocas y formatos. ${ }^{19}$

I6. Ernst H. Gombrich, Aby Warburg. An intellectual Biography (Londres: The Warburg Institute, 1970).

17. Erwin Panofsky, Studies in Iconology. Humanistic Themes in the Art of the Renaissance (Nueva York: Oxford UP, 1939).

I8. Martin Warnke, "Erwin Panofsky - Kunstgeschichte als Kunst", en Eckart Krause y Rainer Nicolaisen, eds., Zum Gedenken an Erwin Panofsky (1892-1968). Reden aus Anlass der Benennung des Hörsaals C im Hauptgebäude der Universität Hamburg in Erwin-Panofsky-Hörsaal am 20. Juni 2000 (Hamburgo: Hamburg University Press/Verlag der Staats- und Universitätsbibliothek Hamburg Carl von Ossietzky, 2000), 4I-78; cita de la página 64: "ich halte es auch nicht für fruchtbar, weiterhin seine berühmten Interpretationsschemata zu bedenken, die noch niemand, am wenigsten Panofsky selbst, wirklich angewandt hat" (trad. Peter Krieger).

19. Aby Warburg, Studienausgabe, consultado el I3 de junio de 2020, en http://www.war- 


\section{DOI: https://doi.org/10.22201/iie.18703062e.2021.119.2767}

438

PETER KRIEGER

De allí nació la idea de fundar el Índice de Iconografía Política, un archivo de alrededor de 150,000 imágenes, ordenadas por categorías, que revelan cómo la política se expresa en una diversidad de fórmulas visuales. Es una idea iniciada por Warburg durante la primera guerra mundial, cuando coleccionó imágenes, recortes de periódicos y otros materiales visuales para documentar la manía colectiva a favor de una guerra en Alemania. Warnke retomó estos inicios conceptuales y los sistematizó a lo largo de su vida académica, así construyó, junto con sus colaboradores, y gracias a un financiamiento que transfirió del Premio Leibniz que le otorgaron en I99I, el Índice que se dispuso como instrumento de investigación en la Warburg Haus. La consulta del Índex, relacionado con una biblioteca especializada en iconografía política, que comparte el mismo sistema de clasificación, revela las constantes y los cambios de motivos iconográficos que no sólo ilustran, sino también determinan reflexiones y actos políticos a lo largo de los siglos, en diferentes países y sistemas. Cabe mencionar que el Índex tiene un alto enfoque eurocéntrico y abarca principalmente desde la historia del arte medieval hasta la contemporánea. ${ }^{20}$ Las tarjetas del Índice, con la reproducción de la imagen y su ficha técnica, contienen una gran pluralidad tipológica visual, no sólo reducida a la obra de arte, sino que incluyen también fotografías de prensa, anuncios comerciales, hasta postales turísticas (que originalmente fueron enviadas a la familia Warnke). De entre esta diversidad se percibe una dimensión política de la producción visual, analizada por una historia del arte convertida en Bildwissenschaft, "ciencia de la imagen", con base en el pensamiento de Warburg. ${ }^{21}$

burg-haus.de/publikationen/aby-warburg-studienausgabe/); Linda Báez Rubí, El Atlas de imágenes. Mnemosine de Aby Warburg, 2 vols. (Ciudad de México: Universidad Nacional Autónoma de México-Instituto de Investigaciones Estéticas, 20I2); y recientemente: Roberto Ohrt y Axel Heil, eds., Haus der Kulturen der Welt y The Warburg Institute, London, Aby Warburg: Bilderatlas Mnemosyne. The Original (Berlín y Stuttgart: Hatje Cantz, 2020).

20. Una versión global y actualizada del Index está en preparación, el Global Research Index of Political Iconography (GRIPI), concebido por Horst Bredekamp, Peter Krieger y Pablo Schneider.

2I. Entrada de Aby Warburg a su diario, del I2 de febrero de I9I7: "Ich bin Bildhistoriker, kein Kunsthistoriker" (Soy historiador de la imagen, no historiador del arte); véase Michael Diers, Warburg aus Briefen: Kommentare zu den Kopierbüchern der Jahre I950 bis 19I8. Schriften des Warburg-Archivs im Kunstgeschichtlichen Seminar der Universität Hamburg, Band 2 (Berlín: DeGruyter), 230, n. 142. 
Un ejemplo muestra los frutos de esta línea de investigación sobre iconografía política, el artículo sobre la "visualización del poder en el siglo XvI", ${ }^{22}$ donde Warnke explica cómo el Estado (en Europa) se hace visible por medio del diseño urbano y militar, por la expansión de infraestructuras viales, la marcación de fronteras, pero también por escenografías efímeras — en competencia con la presencia urbana de la Iglesia. Warnke indaga, en particular, la configuración y el efecto de un "aparato de ficciones" (Fiktionsapparat) ${ }^{23}$ empleado por el soberano para impresionar a sus súbditos, y con ello, fortalecer su poder —un principio conocido hasta en las campańas electorales de la actualidad. Warnke también describe cómo la creciente abstracción del poder político se compensa por los disfraces del soberano, por su revestimiento con alegorías o incluso con analogías de la naturaleza (el tema visual del soberano como la roca firme en la tormenta marítima). Son estrategias visuales claramente dirigidas a los destinatarios, los subordinados, entonces, son principios de lo que hoy día se denomina comunicación visual o public relations.

Dentro de este programa de la producción visual de poder político, Warnke también analizó la contribución de los artistas, en especial los adscritos a las cortes. Su "habilitación" (tesis posdoctoral, necesaria para obtener una cátedra como profesor universitario) enfocó esta cuestión. Su libro El artista cortesano de 1985, con base en su "habilitación" de 1969, enfocó una historia social del arte que invirtió una noción establecida en la historiografía: comprobó que los artistas de la corte, a pesar de ser controlados por el sistema monárquico, ejercían un mayor grado de innovación que el artista comercial que tenía la necesidad de ajustar su obra al gusto, por lo general conservador, del mercado. Con ello, Warnke disolvió un esquema de interpretación que supuso una línea de liberación burguesa que se independiza de la represión monárquica, una perspectiva de emancipación, que, de hecho, era mucho más compleja y controvertida.

Subproductos de esta amplia investigación fueron las monografías sobre Rubens ${ }^{24}$ y sobre Diego Velázquez; ${ }^{25}$ este último claramente fomentó los entonces poco desarrollados estudios hispánicos dentro de la historia del arte en Ale-

22. Martin Warnke, "Visualisierung der Macht im I6. Jahrhundert", en Jörg-Dieter Gauger y Justin Stagl, eds., Staatsrepräsentation (Berlín: Reimer, 1992), 63-74.

23. Warnke, "Visualisierung der Macht im I6. Jahrhundert", Staatsrepräsentation, 73.

24. Martin Warnke, Peter Paul Rubens. Leben und Werk (Colonia: DuMont Buchverlag, 1977).

25. Martin Warnke, Velázquez. Form \& Reform (Colonia: DuMont Buchverlag, 2005). 


\section{DOI: https://doi.org/10.22201/iie.18703062e.2021.119.2767}

440

PETER KRIEGER

mania. ${ }^{26}$ El image making de Velázquez para el rey Felipe IV también fue un aspecto desarrollado en un texto corto sobre el servicio del arte a la política, ${ }^{27}$ un trabajo que provocó, de manera productiva, a toda la comunidad de investigadores del arte moderno y contemporáneo en Alemania, con claras repercusiones para el debate internacional. Con elegancia intelectual y una dosis de ironía, Warnke constató que, lo que ahora se realiza desde los medios masivos como la televisión, las redes sociales y el internet, el maquillador — físico o virtual- cumple con la función escenográfica que alguna vez correspondió al pintor de la corte, como Velázquez — y no el artista contemporáneo, que trabajaba en la marginalidad. Mientras el creador premoderno se ubicó en un esquema funcional de política, religión y cultura, afirmando al poder —aun criticándolo como lo hizo Goya en la corte al retratar, en I8oI, a la familia monárquica de Carlos IV con tintes de demencia-, en tiempos actuales ya no se requiere del artista para ello, porque sus funciones las cumplen los diseñadores de estrategias publicitarias, fotógrafos, camarógrafos, cutters, maquillistas e incluso cada usuario de celular y redes sociales; en una palabra, las artes de servicio mediático reemplazan a las artes plásticas. Antes la pantalla de televisión y ahora las computadoras y dispositivos electrónicos se encargan de crear nuevas opciones y técnicas visuales, lo que fue desempeñado durante siglos por las artes tradicionales — aunque, y esto lo subrayó Warnke, usando las mismas estrategias escenográficas. En términos de la historia del arte como historia de los medios, Warnke constató que la fotografía (incluyendo las imágenes móviles) ha socavado el monopolio milenario de mimesis que tuvieron los pintores. También destacó que durante el siglo xx (después de la primera guerra mundial), sólo los regímenes totalitarios mantuvieron a los artistas plásticos para fines propagandísticos ${ }^{28}$ mientras las democracias casi ya no produjeron arte estatal afirmativo, sino más bien, arte desde la distancia crítica —un aspecto interesante también para la revisión, por ejemplo, de la obra de Diego Rivera en México.

26. Cabe mencionar que, a pesar de su origen brasileño, su dominio perfecto del portugués y avanzado del español, Warnke no incluyó el arte latinoamericano en sus investigaciones; sólo mantuvo en su memoria la selva brasileña donde vivió y sus viajes a las metrópolis latinoamericanas como adolescente.

27. Martin Warnke, "Die zu sich selbst entlassene Kunst", en Im Blickfeld. Jahrbuch der Hamburger Kunsthalle, núm. 3 (1998): I55-162.

28. Al respecto véase también Dawn Ades y Tim Benton, Art and Power. Europe under the dictators 1930-1945 (Londres: South Bank Centre/Thames and Hudson, 1995). 
Warnke concluyó ese artículo con una provocación para la historiografía del arte moderno: que la corriente vanguardista en artes plásticas, de hecho, no luchó por su libertad de expresión, sino que fueron despedidos del contrato social; sus servicios ya no eran necesarios y, en consecuencia, se refugiaron en las esferas autorreferenciales de las galerías y museos. Por lo menos, Warnke concede al final de su breve texto, que las vanguardias contienen el potencial de generar una distancia crítica y una contrapropuesta a "los ataques propagandísticos, a nuestras capacidades de percibir y pensar", ${ }^{29}$ a los estándares visuales de nuestra cultura política.

Expongo este resumen en el obituario extendido de Martin Warnke no sólo porque el contenido es accesible sólo en alemán, sino por la importancia de esta línea de investigación que ha aportado contribuciones relevantes al avance del conocimiento en nuestra disciplina, además de que el formato en que lo publicó, la primera versión de este texto para la revista anual del museo de arte en Hamburgo salió en un periódico; es el formato de la miniatura, sin aparato crítico, pero con alta competencia intelectual, que Warnke utilizó como plataforma para lanzar sus ideas novedosas — un formato despreciado en tiempos actuales de represión bibliométrica y de fijación en el artículo publicado en revista indexada como única prueba de inteligencia en las humanidades.

Dos ejemplos más perfilan este espíritu de enfocar un tema actual, controvertido, y presentarlo a un amplio público de lectores, más allá de los reducidos círculos de las publicaciones especializadas en historia del arte.

En 1999, cuando el artista contemporáneo Hans Haacke propuso su instalación "A la población" para materializarla en el parlamento alemán restaurado en Berlín, Warnke intervino con una breve, aguda y bien informada respuesta. El artista conceptual, orientado claramente al espectro político de izquierda, propuso la acumulación de porciones de tierra de los 669 distritos electorales de la República Federal de Alemania en el patio del Reichstag, la sede del parlamento. Era un proyecto que provocó un debate en el propio parlamento, y a unos días antes de la votación a favor de su realización, Warnke puso a consideración, en un artículo para un periódico, ${ }^{30}$ que este concepto tiene un origen conceptual incómodo, inapropiado para celebrar la democracia: en 1940, al primer ańo de la segunda guerra mundial, encontraron una tumba medie-

29. Warnke, "Die zu sich selbst entlassene Kunst", I62.

30. Martin Warnke, "Haakes Haken. Reichstag, Erde und NS-Zeit”, Süddeutsche Zeitung, 29 de marzo de 2000 . 


\section{DOI: https://doi.org/10.22201/iie.18703062e.2021.119.2767}

\section{2}

PETER KRIEGER

val en la iglesia de la ciudad alemana de Quedlinburg. Por órdenes del entonces jefe de la SS, Heinrich Himmler, uno de los responsables del terror estatal nazi y el holocausto, rediseńaron esta tumba con urnas que contenían tierra de todas las circunscripciones territoriales (Gaue) del "imperio" alemán, con una extensión para urnas de los territorios conquistados durante la guerra. Así, a pesar de la posible codificación múltiple del acto de acumular y monumentalizar porciones de tierra, por sentidos esotéricos, regionalistas o incluso socialistas, Warnke rechazó el proyecto de Haacke por el "copatronato" conceptual con uno de los peores personajes en la historia de la humanidad. Finalmente aprobaron el proyecto con una mayoría escasa, ${ }^{31}$ pero hubo un debate intenso sobre el arte contemporáneo en el parlamento alemán, un interesante caso ampliamente debatido, en parte, por la intervención pública de Warnke.

De formato semejante fue un breve artículo en la prensa, y también de carácter provocador, sobre un gesto popular del entonces papa Juan Pablo II: el beso de la tierra sobre la pista de aterrizaje en varios aeropuertos internacionales, con las llegadas misioneras del máximo representante del Estado del Vaticano. Equipado por su determinación luterana, mencionada al inicio de este obituario, Warnke puso en duda el derecho del papa para besar tierras ajenas al Vaticano porque este gesto simboliza un reclamo de apropiación. Aunque los católicos en los países visitados por el Pontifex Maximus lo interpretaban como un gesto de humildad y de homenaje a la nación de que se tratara, es innegable su relación con lo que aclara una fuente iconográfica del siglo XVII que Warnke reveló: se trata de una tradición ceremonial definida por Emanuele Tesauro en su Cannocchiale Aristotelico, un influyente manual de poesía barroca, publicado por primera vez en I654, ampliado en I670, con un total de nueve reediciones hasta 1702 . En el tercer capítulo está definido que el acto de besar la tierra es símbolo de una futura propiedad, en el original italiano: "Quinci il baciar la terra, rimase in Simbolo presago di scuro posseso." El origen narrativo de este tema está en una escena del rey Tarquinio, quien, asesorado por un oráculo, quiere observar a aquel de sus tres hijos quien primero se acerque a besar a su mamá. Su hijo Junius Brutus besa en un inicial momento a la "madre tierra" y recibe el nombramiento de soberano. Un gesto conocido también por Julio César, quien tuvo un accidente y se cayó llegando a

3I. Con 260 a favor y 258 votos en contra del proyecto, y 3I abstenciones, las votaciones se llevaron a cabo el 5 de abril de 2000; véase Süddeutsche Zeitung, 6 de abril de 2000 y Drucksache I4/2867 des Deutschen Bundestages. 
África y, para rescatar la vergonzosa situación, besó la tierra que iba a conquistar, aclamando "Teno África". Razón para advertir que besar la tierra es signo de un supuesto dominio y sumisión de los territorios visitados. Warnke confirma la validez del gesto también con un episodio no muy lejano, en el año 198I, cuando el rey Constantino II regresó a Grecia a reclamar su reino perdido, se puso de rodillas y besó la tierra. Hasta en el deporte está presente este gesto: antes del maratón en las Olimpiadas de 1988 en Seúl, el corredor italiano besó la tierra de la competencia, que finalmente ganó. Tomando en cuenta estos diferentes escenarios simbólicos, Warnke especuló si los asesores de Karol Wojtyla le aconsejaron este gesto para manifestar un derecho de supremacía y, en consecuencia, se preguntaba si los presidentes extranjeros que visitan al Vaticano tendrán el derecho de besar la tierra alrededor de la Basílica de San Pedro.

Son estas miniaturas, provocadoras y bien sustentadas, las que perfilan las chispas intelectuales de Warnke. En la última década de su vida, marcada por el cáncer, escribió varios textos cortos que, por su erudición, enriquecieron los debates intelectuales en la Bildwissenschaft y, en especial, sobre cuestiones de iconografía política. Una de sus últimas intervenciones versó sobre un problema humano actual y preocupante, la migración, tema también de su propia vida desde su emigración de Brasil, donde vivió como minoría étnica y religiosa, a Alemania. En buena tradición warburgiana compuso varias tablas con imágenes de la migración, expuestas en la Warburg Haus y publicadas en una revista de historia de las ideas, con el título de "Refugiado sin 'coyote". ${ }^{32}$ Incluyó escenas del escape de los hugonotes a finales del siglo XvII, pinturas de refugiados económicos llegando a los Estados Unidos a finales del siglo XIX, y fotografías de Alfred Stiglitz con masas de emigrantes acorralados en barcos transatlánticos, así como fotografías contemporáneas de botes neumáticos repletos de africanos en el mar mediterráneo. En estas y otras imágenes, Warnke define el acto de emigración como forma de resistencia en contra de cualquier represión política, religiosa, o simplemente por hambre. ${ }^{33} \mathrm{Al}$ aludir a un tema de Aby Warburg, las imágenes de la emigración son un Leidschatz de la existencia humana, un archivo visual del sufrimiento. Es consecuente que la última obra de Martin Warnke exprese la ética y relevancia de su trabajo académico.

32. Martin Warnke, "Flüchtling ohne Schlepper. Aus dem Bildindex zur politischen Ikonographie", en Idee. Zeitschrift für Ideengeschichte, núm. 2 (2016): 65-74.

33. Jost Philipp Klenner, "Bildindex zur Politischen Ikonographie. 485: Untertanen-05: Auswanderer / Emigranten”, Idee. Zeitschrift für Ideengeschichte, núm. 2 (2016): 66. 
444

PETER KRIEGER

Postscriptum: las tardes en la Warburg Haus, cuando revisé las imágenes del Índice de Iconografía Política en un diálogo inspirador con Warnke, han sido unos de los momentos más intensos de mi propia vida académica. Martin Warnke fue un maestro clave a lo largo de mis estudios de historia de la imagen. $\quad$ s 